\title{
O suicídio e a morte do narrador
}

\author{
Maria Lívia Tourinho Moretto ${ }^{a}$ \\ Bernardo Parodi Svartman ${ }^{b}$ \\ Cintia Copit Freller"* \\ Gustavo Martineli Massolab \\ José Leon Crochík ${ }^{c}$ \\ Pedro Fernando da Silva ${ }^{c}$ \\ a Universidade de São Paulo, Instituto de Psicologia, Departamento de Psicologia Clínica. São Paulo, SP, Brasil \\ 'Universidade de São Paulo, Instituto de Psicologia, Departamento de Psicologia Social e do Trabalho. São Paulo, SP, Brasil \\ 'Universidade de São Paulo, Instituto de Psicologia, Departamento de Psicologia da Aprendizagem, do Desenvolvimento \\ e da Personalidade. São Paulo, SP, Brasil
}

Este editorial expressa nossas reflexões sobre o suicídio e a morte do narrador na literatura acadêmica contemporânea, a qual, conforme compreendemos, relaciona-se com outra fatalidade ainda mais grave: as ocorrências atuais de suicídio de jovens. Essa trágica "solução" tem ocupado lugar de destaque na mídia desde a estreia da série americana 13 Reasons Why (2017), dirigida por Brian Yorkey, inspirada no livro homônimo de Jay Asher, e da ampla e controversa divulgação do suposto jogo online Baleia azul, seguidas pelo crescente interesse por ambos. Nosso objetivo é discutir sobre uma possível relação entre o suicídio que se consuma como resultado da morte em vida, desvelando a continuidade funesta entre a fatal autoimposição de um término à vida e a fatídica vida imposta àqueles que estão impedidos de experimentá-la como sujeitos, e o suicídio do narrador na literatura acadêmica que paradoxalmente expressa a submissão do autor às exigências irracionais da maquinaria produtiva que o anula e, com isso, retira o encanto da narrativa.

Se a declarada frustração de Nietzsche (1887/1998), que tão bem conheceu a decadência, em relação à expectativa de que suas obras pudessem ser objetos da leitura como arte já fora há muito uma crítica tenaz ao "homem moderno", incapaz de ruminar o conteúdo de sua leitura, a empobrecida experiência intelectual propiciada pela forma padrão adotada pelo modo atual de divulgação científica, $o$ relato de pesquisa sem reflexão teórica, parece supor uma regressão ainda maior do leitor, de modo que à morte do narrador equivale a anulação do trabalho interpretativo do leitor. Se o suicídio de jovens provoca angústia imediata e sugere rápido entendimento de que a vida foi tragada por suas contradições objetivas, o fenômeno paralelo que ora enfatizamos, o suicídio do narrador, parece não promover igual compreensão.

A asseveração de Nietzsche pode ser pensada à luz da crítica que Walter Benjamin (1936/1994) fez à cultura já explicitamente em decadência algumas décadas depois: "Por mais familiar que seja seu nome, o narrador não está de fato presente entre nós, em sua atualidade viva" (p. 197). Esse arguto crítico da cultura, que diante do fatídico cerceamento de sua vida pelas forças nazistas, que implicava

* Endereço para correspondência: revpsico@usp.br também a aniquilação da vida de milhões de seus iguais, pôs fim à própria vida, pôde revelar que a vida ceifada pelo suicídio é a mesma vida já mortificada pelo predomínio das instâncias opressivas que anulam a possibilidade de compartilhar experiências, tal como foi possível por meio da narração. Em uma de suas mais célebres formulações, Benjamin pôde registrar para uma posteridade que ainda não conhece o além do homem "moderno", rejeitado por Nietzsche, a relação entre o declínio do narrador e a experiência da catástrofe objetiva representada pela guerra, cujo terror se generalizou para as estáveis instituições do mundo administrado:

Com a guerra mundial tornou-se manifesto um processo que continua até hoje. No final da guerra, observou-se que os combatentes voltavam mudos do campo de batalha não mais ricos, e sim mais pobres em experiência comunicável. . . nunca houve experiências mais radicalmente desmoralizadas que a experiência estratégica pelas guerras de trincheiras, a experiência econômica pela inflação, a experiência do corpo pela guerra de material e a experiência ética pelos governantes. (Benjamin, 1936/1994, p. 198)

A experiência da guerra vivida em suas múltiplas dimensões e efeitos daninhos para a existência dos sujeitos produz uma torrente de conteúdos incomunicáveis; produz um tipo de emudecimento que já é parte da efetivação da morte em vida. A impossibilidade de narrar, que atinge seu cume na proximidade com a morte que poderia ser mitigada pela possibilidade de transmitir experiências e sabedoria, intensifica o sofrimento de uma vida de sacrifícios, permeada pelos determinantes da civilização repressiva, de modo a conferir à morte a função de instrumento de repressão. Marcuse (1955/1981), que considerou a possiblidade da morte sem angústia, desatrelando-a de um sofrimento transcendental para desvelar sua relação com a vida objetiva, não hesitou em criticar a sociedade que faz da ameaça um ethos existencial caracterizado pela abdicação e submissão: “. . . a educação para o consentimento da morte introduz um elemento de abdicação na vida, desde o princípio - abdicação e sacrifício" (p. 203). A impossibilidade de narrar o vivido mal assimilado indica 
que a falência do narrador remonta a disposições objetivas, mas a resignação diante da degradação da vida produzida por essas disposições significa renúncia da vida que ainda existe e poderia representar a negação desse processo regressivo. Narrar o inenarrável é uma tarefa que requer uma postura de sujeito mesmo quando o próprio sujeito está negado pela existência opressiva. A morte do narrador implica uma triste similitude entre a negação da narração dos sofrimentos dos jovens que abdicam da vida e a negação da condição de sujeitos dos autores que abdicam da possiblidade da narração em prol do relato informativo de pesquisa: "Se a arte da narrativa é hoje rara, a difusão da informação é decisivamente responsável por esse declínio" (Benjamin, 1936/1994, p. 203).

Diante dessa funesta similitude, cabe considerar que as questões relacionadas ao preocupante suicídio de jovens são também expressão da degradação da experiência, da impossibilidade de narrar o inenarrável, pois remete a um quantum de sofrimento que não pode ser suportado pelo interlocutor: ". . . desaparece o dom de ouvir, e desaparece a comunidade dos ouvintes" (Benjamin, 1936/1994, p. 205). A experiência que deveria conectar o que fora experimentado pelo indivíduo a outros, por meio da referência comum a algo presente na cultura como tradição, é interditada tanto pelo que foi vivido como horror quanto pela deterioração da capacidade de entrar em contato com a experiência do outro, favorecendo o isolamento monadológico. Esse isolamento expressa a acomodação a uma ordem social que nega a vida plena e requer que, prejudicadas na expressão da individualidade, as pessoas adiram ao jogo proposto pela dominação, de modo a se arriscarem e a negarem a própria vida.

Na série 13 Reasons Why, a adolescente Hannah Baker, marcada pela experiência de bullying em uma escola norte-americana, retrata seu sofrimento por meio da gravação em fitas nas quais registra o que, para ela, são as razões pelas quais ela teria dado fim à sua própria vida. O que não pôde comunicar em vida, ficou registrado para uma possível audiência que, contraditoriamente, prolonga sua existência para além da morte que já experimentara ao ter de registrar para uma posteridade incerta o que necessitava ser comunicado de imediato; sendo indicativo da impossibilidade de ser escutada por seus pares.

Baleia azul é um suposto jogo online que teria surgido na Rússia e que, ainda que seja, do ponto de vista da realidade, um fato a ser comprovado, já apresenta seus efeitos reais e exige nossa atenção. $\mathrm{O}$ jogo dar-se-ia por meio da relação entre o jogador - que voluntariamente se apresenta nessa condição - e os curadores - que são os que administram o jogo. Este, por seu turno, envolve a proposta de uma série de cinquenta tarefas, todas apresentadas como desafios arriscados que os jogadores devem cumprir gradativamente. Muitas dessas tarefas envolvem desafios, comumente atos de automutilação, até que, para "ganhar o jogo", o jogador deve cumprir o desafio final: tirar a própria vida. Nesse caso, a "decisão" de por fim à própria vida, que legalmente é compreendida como suicídio, expressa a submissão a uma autoridade externa, anônima, que induz à morte. $\mathrm{O}$ suicídio induzido parece encobrir o assassinato, assim como no caso do autoisolamento do indivíduo, que é propiciado pela rejeição dos outros e é considerado um problema individual, quando, efetivamente, é gerado socialmente; não é casual que se considerem, geralmente, os distúrbios psíquicos como causa do suicídio e do autoisolamento (uma forma de suicídio social, mas claramente fomentado pelo incentivo ao individualismo e à sobrevivência do mais apto).

Em relação a um contexto político-econômico bastante distinto, mas semelhante no que concerne ao poder de determinação externa da destruição da vontade individual, Marx (1846/2006), para quem o poder financeiro não foi negligenciado, destacou dentre as causas do suicídio ". . . a exoneração de funcionários, a recusa de trabalho, a súbita queda dos salários, em conseqüência de que as famílias não obtinham os meios necessários para viver, tanto mais que a maioria delas ganha apenas para comer" (p. 48), e demonstrou acuidade psicológica ao considerar que em determinadas circunstâncias - como a de uma jovem de Martinica subjugada pelo marido ciumento, que a trancafiava em sua própria casa, levando-a ao desespero de tirar a própria vida - o suicídio é, na verdade, assassinato: "Certamente, para todos aqueles que não reduzem o espírito pleno das palavras às letras que as formam, esse suicídio foi um assassinato, praticado pelo esposo; mas foi também o resultado de uma extraordinária vertigem de ciúme" (p. 41). O patriarcalismo e o direito de propriedade, asseguradas pelo Código Civil da época, foram essenciais para que a opressão exercida pelo patriarca déspota induzisse a jovem ao suicídio. O macabro jogo Baleia azul parece compreender resquícios de uma autoridade externa que hoje prescinde da imposição, pois já está internalizada por aqueles que durante séculos aprenderam a obedecer.

Note-se que tanto a série quanto o jogo abordam o tema do suicídio, mas há, do nosso ponto de vista, diferenças cruciais no modo pelo qual cada um faz a abordagem do tema, e a elucidação dessas diferenças é importante para a compreensão da análise que estamos propondo sobre o problema.

Na série, a morte é, para Hannah, a solução que dá fim a uma vida já desgastada pela impossibilidade da experiência, emudecida pela carência de uma comunidade de ouvintes, na qual a esperança ruiu; temos, então, a morte apresentada como fim da vida, como ruptura provisória a um sofrimento que a transcende e somente pôde ser comunicado mediante seu sacrifício; suas dores ecoam na dor de quem for capaz de ouvi-la. No jogo, a morte é apresentada como meio que empresta sentido a uma vida debilitada: temos, neste caso, a morte apresentada como meio de experimentar desesperadamente a vida que é negada, como continuidade da impotência que a impede, e já se manifestava na morte em vida.

Em ambas situações, a totalidade social se exerce brutalmente sobre o particular fragilizado. Hannah foi violada pela insensibilidade daqueles que a reduziram a uma imagem estereotipada, arrancada de sua condição de 
sujeito autônomo; os jovens capturados pelo Baleia azul parecem demonstrar uma fragilidade ainda maior, pois são conduzidos por uma ordem anônima que parafraseia a ordenação social homicida. Nesse caso, a necessidade de viver algo que intensifique e agregue sentido à existência fragilizada é permeada pela ameaça que impede qualquer tomada de consciência e autonomia quanto à possibilidade de sair do jogo.

Ainda que sejam reconhecidas especificidades do problema do suicídio nas duas situações, sabe-se, também, que onde há ruptura também há continuidade. Buscamos enfatizar a discussão a respeito da posição subjetiva dos jovens que se apresentam como presas fáceis do "Baleia", a ponto de se alienarem em um jogo no qual a morte é o que daria algum sentido para continuar a vida.

As estatísticas crescentes (Organização Mundial de Saúde, 2014), inclusive no contexto brasileiro (Fideles, 2016) em todas as faixas etárias - em especial entre os jovens e adolescentes -, expressam, sem deixar margem à dúvida, a gravidade do problema. Pela dimensão do problema já é considerado concernente também ao campo da Saúde Pública.

No entanto, os especialistas entendem que o assunto tende a ser, inclusive nos meios técnicos e entre os profissionais da área, tratado frequentemente como tabu, o que dificulta, sobremaneira, a construção de estratégias mais realistas para o enfrentamento do problema, especialmente em situações nas quais, ciclicamente, tem-se de lidar com a ocorrência de "epidemias pontuais de comportamentos suicidas protagonizadas por crianças e adolescentes que nos obrigam a um estudo mais aprofundado das características do comportamento suicida na juventude". (Kuczynski, 2014, p. 246)

Se é possível que o modelo de imitação responda por parte dos casos de suicídio e de tentativas de suicídio entre adolescentes a partir de influência midiática, como supõem Loureiro, Moreira e Sachsida (2013), cabe destacar que essa possiblidade de que as pessoas sucumbam à imitação irrefletida nos intriga e preocupa. Sem supervalorizar o poder de influência dos meios de comunicação de massa, sobretudo ajustados à forma da indústria cultural, é preciso reconhecer que a mediação por eles exercida intensifica ainda mais o distanciamento e a superficialidade da comunicação, de modo a impedir a troca de experiências. Em uma sociedade hierarquizada como a nossa, em cuja forma de organização estão incrustradas relações de poder caracterizadas pelo autoritarismo e pela submissão, o autoritarismo dos meios de comunicação já cumpre um papel questionável de preparação de uma recepção cativa; todavia, não se pode desconsiderar o papel exercido pelas pressões sociais que antecedem essa influência, limitando as possibilidades de participação efetiva nos processos sociais decisivos. Do nosso ponto de vista, o fato de haver uma suposição generalizada de que falar sobre suicídio possa induzir suicídios não deveria justificar a tendência ao silenciamento, nem conservar o caráter de tabu atribuído ao tema. Nessa desconfiança, que se limita a uma compreensão mecanicista, há também um importante elemento de verdade: não basta falar de suicídio, como levianamente fazem muitos produtos da indústria cultural, mas de discutir seriamente os fatores que o geram. A esse respeito, não se pode negligenciar o alcance da análise desenvolvida por Marx: "A classificação das diferentes causas do suicídio deveria ser a classificação dos próprios defeitos de nossa sociedade" (1846/2006, p. 44).

A literatura médica, por meio do que Phillips (1982) chamou de "efeito Werther", faz referência à ideia de que o tema do suicídio é "contagioso" como o demonstra a epidemia de suicídios entre jovens atribuída à identificação dos adolescentes da época com o protagonista da obra escrita por Goethe (1774/2002), intitulada Os sofrimentos do jovem Werther, na qual o jovem Werther se suicida em resposta a um impedimento amoroso (Brunhari \& Moretto, 2015). Não obstante a desventura amorosa de Werther, seu suicídio também compreende o sofrimento decorrente da percepção da flagrante falsificação da experiência. Nas magistrais palavras de Goethe (1774/2002), a dimensão subjetiva do sofrimento sofrido por seu personagem era também permeada por fatores próprios da totalidade social, por fatores objetivos:

A vida humana não passa de um sonho. Mais de uma pessoa já pensou isso. Pois essa impressão também me acompanha por toda parte. Quando vejo os estreitos limites onde se acham encerradas as faculdades ativas e investigadoras do homem, e como todo o nosso labor visa apenas a satisfazer nossas necessidades, as quais, por sua vez, não têm outro objetivo senão prolongar nossa mesquinha existência; quando verifico que nosso espírito só pode encontrar tranquilidade, quanto a certos pontos das nossas pesquisas, por meio de uma resignação povoada de sonhos, como um presidiário que adornasse de figuras multicoloridas e luminosas perspectivas as paredes de sua célula... tudo isso, Wilhelm, me faz emudecer. (p. 226-227)

A vida objetiva que emudece e, inclusive, interdita as possibilidades de superação positivas do sofrimento, dentre elas o amor, também se manifesta em Werther ${ }^{1}$. $\mathrm{O}$ receio, portanto, de colocar o suicídio em evidência para os jovens e incentivar o ato justificaria, para alguns, a tendência ao silenciamento como forma (ilusória, é preciso dizer) de evitar a angústia e a impotência comumente provocadas pela aproximação ao tema. E mesmo sem concordar que o silenciamento represente uma condução adequada, é preciso reconhecer que, de fato, o contato com os sofrimentos alheios desperta angústia e nos lembra de

\footnotetext{
1 A esse respeito, Benjamin (1928/2009) destaca: "Nos humores de Werther desenrola-se o mal du siècle da época em todas as suas nuanças. Werther - eis aí não apenas o amante infeliz que, em seu desespero, encontra um caminho rumo à natureza. . .; ele é também o cidadão cujo orgulho se fere nas barreiras de sua classe e que, em nome dos direitos humanos, até mesmo em nome da criatura, exige seu reconhecimento". (p. 131)
} 
nossa impotência objetiva. Não se trata de falar sobre o suicídio, mas de desvendar e de discutir os sofrimentos que se relacionam com ele, inclusive, a falência da comunicação. Além disso, caso sejam postos em discussão os motivos que levam à morte em vida, talvez, muitas vidas poderiam ser poupadas.

Sem contestar a sequência inegável dos fatos, para nós, no entanto, a "tese" que valoriza o potencial de contaminação do tema do suicídio, na qual falar de suicídio é induzir a suicídios (Côrte, Khoury, \& Mussi, 2014), carece de análise crítica, uma vez que não justifica, por si só, como contesta Durkheim (1897/1977), nem o ato suicida em si, nem a tendência a tomá-lo como tabu.

Tal como alega Adorno (2000) em relação à educação escolar, nenhum medo deveria ser reprimido, pois, se isso ocorre, pode retornar sob a forma de violência; caberia expressá-lo. Isso também pode ocorrer com a questão dos sofrimentos ocultados pelo silenciamento que recobre o suicídio; o represamento da discussão pode fazer que as tendências a ele ligadas acarretem outros problemas, como a culpa por julgar (erroneamente) que é um problema individual, o que poderia provocar outras formas de sofrimento psíquico, dentre as quais a depressão e, assim, aproximar contraditoriamente o indivíduo do que deveria ser evitado pelo silêncio.

É claro que, mais do que sensibilidade, falar sobre os fatores relacionados ao suicídio requer coragem e disponibilidade para reconhecer e, em alguns casos, enfrentar as dificuldades associadas ao problema. Nossa posição sobre isso é clara: quanto mais inquietante e espinhoso o assunto, mais arriscado é silenciar sobre ele. Entendemos que cabe ao pensamento científico e filosófico, para além de apresentar as tão relevantes e preocupantes "estatísticas" sobre o problema, promover a abertura à fala, lançar luz e ampliar as oportunidades de debate, produzindo reflexão crítica, sobretudo porque entendemos que o falatório mal fundamentado a respeito de temas polêmicos não só aumenta o pânico em relação a eles como reforça a relação entre a falência da formação e a vulnerabilidade diante de processos destrutivos como os que estão em questão. O tema do suicídio nos lembra de nossa limitada capacidade de estabelecer experiência, de nos comunicarmos efetivamente uns com os outros. Seria preciso uma escuta efetiva que, contrariando o Zeitgeist, fosse suficiente para sustentar que o que é indizível para uma pessoa não equivale, necessariamente, ao que é inaudível para nós.

Por ser um tema multifacetado é possível encontrar na literatura especializada cerca de quinze definições sobre o suicídio (Kuczynski, 2014), sendo consensual a concepção de que, diferente da ideação suicida e da tentativa de suicídio (Turecki, 1999), o suicídio é o ato por meio do qual uma pessoa dá fim à própria vida, provavelmente por ser 0 modo que ela encontrou para dar fim à dor de existir. Para os propósitos deste trabalho e como exemplo da variedade de compreensões acerca do tema, além dos elementos teóricos já apresentados, entendemos que também vale a pena recuperar algumas contribuições da perspectiva psicanalítica e outras próprias da reflexão sociológica a respeito do tema, as quais podem contribuir para ponderações que remetem à relação entre indivíduo, cultura e sociedade.

Para a perspectiva psicanalítica, a hipótese de Freud (1917/1974), nestes casos sustentada pelos conceitos de ato e de melancolia, articula necessariamente as noções de insuportável e de irrepresentável, das quais se depreende que aquilo que é da ordem do insuportável e que escapa à palavra pode encontrar saída pela via do ato suicida (Brunhari $\&$ Moretto, 2013).

Seguindo o pensamento freudiano sobre o tema, Lacan (1962-1963/2005, 1967-1968/no prelo) considera o suicídio por meio da articulação entre os conceitos de angústia, ato psicanalítico e de objeto "a", apresentando este último como o articulador que, em sua teoria, corresponderia ao insuportável da teoria freudiana. Sua contribuição mais original sobre o tema se dá pelo avanço na conceituação de "passagem a ato" e de "acting-out", indicando que a diferença entre ambos é um elemento fundamental no manejo clínico desses casos. Para ele, o ato suicida é a vitória do gozo da morte contra o desejo de saber. É nesse sentido que Lacan (1967-1968/no prelo) refere-se ao ato suicida como o único ato humano bem-sucedido, contrapondo-o ao ato falho que, por sua estrutura, admite a abertura a uma série inacabada de novas possibilidades de sentido e construção de novos saberes. Interessante, neste ponto, contrapor a perspectiva de Camus (1942/1989), para quem a resistência ao absurdo da vida que impele ao suicídio e pode evitá-lo seria um ato humano "bem-sucedido".

Dito de outro modo, se a experiência clínica possibilita uma compreensão teórica a respeito do ato suicida, é preciso ressaltar que todo avanço e construção de saber sobre o tema se faz, sobretudo, pela sua falha. É, necessariamente, a partir da oferta de escuta ao indivíduo cuja tentativa de suicídio não se consumou, seja no âmbito dos serviços de emergência nas instituições de saúde, seja no âmbito da clínica privada, que toda construção de saber sobre o tema se faz possível: nas situações em que o ato suicida é um ato falho.

É então que se tem acesso às frequentes narrativas que indicam a forte relação entre a intenção de morrer e o extremo desinteresse, desinvestimento e/ou perda de força para enfrentar os desafios da existência e para se manter vivo. Ocorre, nessas situações, o que acima chamamos de "morte enquanto ruptura", pela impossibilidade de continuar.

Numa perspectiva sociológica, que enfatiza as relações entre suicídio e sociedade (Rodrigues, 2009), o principal estudo a respeito do tema é o de Durkheim (1897/1977), que o considera um fenômeno social, partindo da premissa de que é a forma da coletividade que determina as atitudes individuais (Teixeira, 2002).

Para Durkheim (1897/1977), o suicídio varia na razão inversa do grau de integração do grupo social a que pertence, de tal modo que propõe quatro tipos de suicídio: egoísta, altruísta, anômico e fatalista. Os dois primeiros se relacionam com as forças de integração social (reduzidas no suicídio egoísta e excessivas no altruísta), enquanto os 
dois últimos se relacionam com a regulação social (reduzidas no suicídio anômico e excessivas no suicídio fatalista) (Coutinho, 2010).

Fizemos referência, brevemente, a duas mortes (ruptura e continuidade) como posições subjetivas. A morte como ruptura é quando uma pessoa resolve pela sua saída de cena, é o fim que alguém dá a uma vida vazia de sentido, ou sem esperança de ter experiências, insuportável, ainda que sua vida continue, como memória do outro. Nesse sentido, o suicídio é a escolha pelo fim de uma vida quando ela chega ao limite da impossibilidade (Carvalho, 2014). A morte como continuidade é o que chamamos de "morte em vida", é o meio pelo qual alguém, desesperado para manter-se vivo, busca desafios por meio do flerte com a morte. Nesse caso, o "jogador" ao invés de sair, ele próprio, de cena, coloca a morte em cena como meio para dar algum sentido e suportar sua vida.

Se um dos aspectos que consideramos para a análise dessa posição subjetiva foi o suicídio entre jovens, não é nele que esta análise se encerra, pois nosso desafio é construir hipóteses que nos permitam compreender a que essa posição subjetiva - que chamamos de "morte em vida" - responde e o que ela nos ensina a respeito das relações entre indivíduo e sociedade.

Nossa tendência é entender essa mortificação em vida como uma das possíveis respostas do indivíduo às várias formas de controle que regulam as relações sociais, inclusive no campo do trabalho e de seus resultados, chegando ao que nos concerne: o suicídio do narrador, por exemplo, em seus relatos de pesquisa, limitados à descrição empobrecida de fatos, à comunicação de resultados do que já foi pensado, esvaziados de qualquer reflexão e crítica.

Isso nos remete à imagem de adolescentes angustiados que, desesperados para deixar sua marca no mundo, o fazem sem perspectiva ou esforço para realizar qualquer obra (o "baleia azul" das publicações favorece a possibilidade de obra?).

É quase sempre sob uma pressão desmedida diante dos ideais e métricas de sucesso que, desprovido da condição de criticá-los, o indivíduo, ao tomá-los para si como imperativos, sucumbe alienado a um jogo que, sem trégua, não favorece o estabelecimento de limites, nem a emergência de modos de subjetivação afinados com a criatividade e com a singularidade (Moretto, Kupermann, \& Hoffmann, 2017); singularidade que nessa sociedade dificilmente é possível, pois, quando muito, o indivíduo pode ser particular e parte dela.

Reafirmamos, portanto, o valor do ensaio (Adorno, 1958/2003) e das demais formas de comunicação científica que, calcadas na reflexão, possibilitam a expressão do pensamento crítico, com autoria, comprometimento, liberdade e originalidade, de modo a assegurar o que, para a psicanálise, indica a vitória do desejo de saber contra o gozo pela morte do autor.

A despeito de suas distintas causas, o suicídio não pode ser compreendido apenas como fracasso do indivíduo doente que sucumbiu a seu desespero, consiste também e principalmente em um complexo processo que, dentre outras coisas, expressa a vitória da vida danificada, comumente experimentada como algo insuportável; tornar-se, então, possível considerar a ruptura que representa em relação às possibilidades de resistir ao que causa sofrimento, bem como a continuidade em relação aos fatores já presentes na vida que segue mortificada: sem que as pessoas possam ser sujeitos de suas decisões.

A "decisão" por dar fim à própria vida, nessa sociedade opressiva, não significa um ato de liberdade de escolha, como talvez pudesse significar em uma realidade livre da dominação (Marcuse, 1955/1981), mas a consumação dos processos repressivos. Essa "decisão" é mediada pela ameaça irrefreável de uma realidade que exige a adaptação completa e, com isso, impõe sacrifícios inomináveis que mesmo em sua mais absoluta normalidade já impedem a experiência e degradam a possibilidade da comunicação, de modo a mortificar a vida que segue o fluxo do desempenho requerido. $\mathrm{O}$ âmbito do conhecimento, do qual fazem parte as publicações acadêmicas, poderia comportar a possibilidade de questionamento a essa lógica irracional, mas, no atual estágio da ciência, no qual impera um cientificismo ajustado à produtividade capitalista, tem promovido a substituição do conhecimento, bem como da sabedoria própria da experiência irredutível à divisão do trabalho científico, pela informação técnico-científica, caracterizada pelo predomínio da linguagem operacional em detrimento dos conceitos, e pelo relato em detrimento quer da reflexão, quer da narração. $\mathrm{O}$ narrador no texto acadêmico indica a existência do sujeito cognoscente, a possibilidade da reflexão crítica e da intervenção por meio do pensamento.

Com a crescente exigência por aumento da produtividade, a produção textual predominantemente proposta também tem sido ajustada a um formato padronizado: o relato de pesquisa sem reflexão. Esse padrão requer um tipo de ênfase no método que dispensa o trabalho de elaboração teórica, adota uma linguagem telegráfica que prejudica a própria expressão e se apoia em um tipo de fundamentação em dados empíricos que limita o alcance do pensamento à suposta comprovação experimental. Em suma: nega o próprio sujeito ou, em outros termos, o autor. Como não é pouco importante que essa condição massivamente proposta pelos periódicos acadêmicos imponha um modelo em relação ao qual não se pode esquivar sem prejuízos, consistindo em uma evidente ameaça ao pensamento e à vida profissional daqueles que trabalham com o conhecimento, cabe se perguntar sobre que tipo de sacrifício é exigido dos autores para assegurarem a continuidade de suas tarefas no cenário das publicações acadêmicas.

Conforme apresentamos neste breve texto, parece-nos que o tipo de adaptação exigida dos autores implica o suicídio do autor, pois anula a condição de sujeito, que asseguraria o pensamento, em favor de descrições formalmente corretas, mas vazias de sentido. A dificuldade de poder resistir a essa tendência indica que também com relação a essa forma de suicídio, tal como a do suicídio analisado ao longo deste trabalho, o jogo proposto pelo 
dominador prossegue por meio da ameaça; o fato de implicar a automutilação e de terminar com a autoaniquilação do autor não significa que seja também um suicídio induzido e, nos termos de Marx (1846/2006), um assassinato? Talvez possamos supor que, a exemplo do suicídio de Walter Benjamin, que expressou o ápice da barbárie objetivada pelos nazistas, Hannah Baker, os jovens que sucumbiram ao jogo Baleia azul e, inclusive, o autor contemporâneo foram, com maior ou menor grau de participação das vítimas, assassinados.

\section{Referências}

Adorno, T. W. (2000). Educação e emancipação (2a ed.). São Paulo: Paz e Terra.

Adorno, T. W. (2003). O ensaio como forma. In T. W. Adorno, Notas de literatura I (J. de Almeida, trad., pp. 15-45). São Paulo, SP: Duas Cidades; Editora 34. (Trabalho original publicado em 1958)

Benjamin, W. (2009). Goethe. In W. Benjamin, Ensaios reunidos: escritos sobre Goethe (M. K. Bornebruch, I. Aron \& S. Camargo, trad., pp. 123-177). São Paulo, SP: Duas Cidades; Editora 34. (Trabalho original publicado em 1928)

Benjamin, W. (1994). O narrador: considerações sobre a obra de Nikolai Leskov. In W. Benjamin, Magia e técnica, arte e política (S. P. Rouanet, trad., pp. 197-221). São Paulo, SP: Brasiliense. (Trabalho original publicado em 1936)

Brunhari, M. V., \& Moretto, M. L. T. (2013). O ato suicida e o hospital: uma clínica possível? A Peste: Revista de Psicanálise e Sociedade, 5(2), 51-66.

Brunhari, M. V., \& Moretto, M. L. T. (2015). O suicídio amoroso: uma proposição metapsicológica. Psicologia em Revista, 21(1), 108-125. doi: https://dx.doi.org/DOI - 10.5752/P.1678-9523.2015V21N1P108

Camus, A. (1989). O mito de Sísifo: ensaio sobre o absurdo. Rio de Janeiro, RJ: Guanabara.

Carvalho, S. (2014). A morte pode esperar? Clínica psicanalítica do suicídio. Salvador, BA: Associação Campo Psicanalítico.

Côrte, B., Khoury, H. T. T., \& Mussi, L. H. (2014). Suicídio de idosos e mídia: o que dizem as notícias? Psicologia USP, 25(3), 253-261. doi: https://dx.doi.org/10.1590/01036564D20140003

Coutinho, A. H. S. A. (2010). Suicídio e laço social. Reverso, 32(59), 61-69.

Durkheim,E.(1977).Osuicídio:estudosociológico(M.G.Luz Cary \& J. Vasconcelos Esteves, trad., 2a. ed.). Lisboa: Presença (Trabalho original publicado em 1897)

Fideles, N. (2016, 20 de dezembro). Suicídio: vamos falar da segunda causa que mais mata jovens no mundo? Brasil de Fato. Recuperado de https://www.brasildefato.com. br/2016/12/20/suicidio-vamos-falar-da-segunda-causaque-mais-mata-jovens-no-mundo/

Freud, S. (1974). Luto e melancolia. In S. Freud, Edição standard brasileira das obras psicológicas completas de Sigmund Freud (J. Salomão, trad., Vol. 14, pp. 243-264). Rio de Janeiro, RJ: Imago. (Trabalho original publicado em 1917)

Goethe, J. W. (2002). Os sofrimentos do jovem Werther. In J. W. Goethe, Fausto \& Werther (A. Maximiliano, trad., pp. 217-315). São Paulo, SP: Abril. (Trabalho original publicado em 1774)
Kuczynski, E. (2014). Suicídio na infância e adolescência. Psicologia USP, 25(3), 246-252. doi: https://dx.doi. org/10.1590/0103-6564D20140005

Lacan, J. (2005). O seminário, livro 10: a angústia. Rio de Janeiro, RJ: Jorge Zahar. (Trabalho original publicado em 1962-1963)

Lacan, J. (no prelo). Oseminário, livro 15: o ato psicanalítico. [S.1.]: [s.n.]. (Trabalho original publicado em 1967-1968)

Loureiro, P. R. A., Moreira, T. B., \& Sachsida, A. (2013). Os efeitos da mídia sobre o suicídio: uma análise empírica para os estados brasileiros. Rio de Janeiro, RJ: Instituto de Pesquisa Econômica Aplicada. Recuperado de http://repositorio.ipea.gov.br/bitstream/11058/2264/1/ TD_1851.pdf

Marx, K. (2006). Sobre o suicídio (R. Enderle \& F. Fontanella, trad.). São Paulo, SP: Boitempo. (Trabalho original publicado em 1846)

Marcuse, H. (1981). Eros e civilização: uma interpretação filosófica do pensamento de Freud (A. Cabral, trad.). Rio de Janeiro, RJ: Guanabara; Koogan. (Trabalho original publicado em 1955)

Moretto, M. L. T., Kupermann, D., \& Hoffmann, C. (2017). Sobre os casos-limite e os limites das práticas de cuidado em psicanálise. Revista Latinoamericana de Psicopatologia Fundamental, 20(1), 97-112. doi: https:// dx.doi.org/10.1590/1415-4714.2017v20n1p97.7

Nietzsche, F. (1998). Genealogia da moral (P. C. de Souza, trad.). São Paulo, SP: Companhia das Letras. (Trabalho original publicado em 1887)

Organização Mundial de Saúde (2014). Preventing suicide: $a$ global imperative. Geneva, GE: WHO.

Phillips, D. P. (1982). The impact of fictional television stories on U.S. adult fatalities: new evidence on the effect of the mass media on violence. The American Journal of Sociology, 87 (6), 1340-1359. doi:10.1086/227596

Rodrigues, M. M. A. (2009). Suicídio e sociedade: um estudo comparativo de Durkheim e Marx. Revista Latinoamericana de Psicopatologia Fundamental, 12(4), 698-713. doi: https://dx.doi.org/10.1590/S141547142009000400006

Teixeira, R. R. (2002). Três fórmulas para compreender "O suicídio" de Durkheim. Interface - Comunicação, Saúde, Educação, 6(11), 143-152. doi: https://dx.doi. org/10.1590/S1414-32832002000200021

Turecki, G. (1999). O suicídio e sua relação com o comportamento impulsivo-agressivo. Revista Brasileira de Psiquiatria, 21(Suppl. 2), 18-22. doi: https://dx.doi. org/10.1590/S1516-44461999000600006 